\title{
El delito de violación de las reglas en la construcción
}

José Hurtado Pozo*

\section{Resumen}

El texto se ocupa del comportamiento punible que, en la legislación suiza, se conoce como violación de las reglas en la construcción (artículo 229). Con tales miras, hace un examen del derecho comparado y se detiene en las principales características de esa figura, con especial consideración al bien jurídico; además, examina las modalidades dolosa y culposa de la descripción típica y las consecuencias jurídico-penales imponibles. Todo ello en el ámbito de la responsabilidad de la empresa.

\section{Palabras clave}

Bien jurídico, construcción, culpa, delito, dolo, empresa, reglas, responsabilidad, sanción, violación.

* Ph. D. Catedrático emérito de la Universidad de Fribourg, Suiza. 


\title{
The Crime of Violation of Rules in Construction
}

\begin{abstract}
The text deals with the punishable behavior that, under Swiss law, is known as violation of rules in construction (Article 229). With such a view, the article makes an examination of comparative law and stops at the inspection of main features of that figure, with special consideration to the legal right; it also examines the intentional and culpable modes of typical description and legal-criminal consequences. All in the field of corporate responsibility.
\end{abstract}

\section{Keywords}

Legal right, construction, guilt, crime, fraud, company rules, responsibility, punishment, violation 


\section{Generalidades}

La construcción, renovación o demolición de edificaciones siempre ha constituido una actividad que implica riesgos para los bienes e intereses de las personas. Peligros que han aumentado notablemente a medida que la técnica e instrumentos para llevarla a cabo han devenido más sofisticados. Al mismo tiempo, estos progresos también han comportado mejoras importantes en la seguridad y previsión de que dichos riesgos se produzcan o se concreten en perjuicio tanto de los propios ejecutantes como de terceros.

Este sector peligroso de la actividad diaria, junto con muchas otras, ha sido uno de los factores que ha conducido a que se califique nuestro sistema comunitario de "sociedad de riesgo" (Beck, 1986); caracterizado por procesos de individualización y de fragmentación social en un contexto modificado sensiblemente por la globalización y las transformaciones tecnológicas. De manera que los peligros se multiplican e intensifican con la posibilidad de desestabilizar las actividades sociales, hasta entonces desarrolladas en condiciones de cierta seguridad; situación que ha dado lugar al florecimiento de diversas regulaciones destinadas a precisar los límites que deben respetarse al realizar actividades riesgosas, pero indispensables para la vida social. Este marco normativo constituye el denominado 'riesgo permitido o autorizado'.

Los riesgos comprometen ya sea los intereses individuales de las personas o los intereses colectivos de la comunidad. Por lo que se incriminan comportamientos a título de delitos contra las personas individuales o de delitos contra la colectividad, los mismos que son caracterizados como delitos de lesión o delitos de peligro (individual o colectivo). De modo que el riesgo puede representar la probabilidad de causar un perjuicio a una persona o a un grupo de personas determinadas o se puede presentar la posibilidad de que el daño afecte a un número indeterminado de individuos.

El comportamiento punible objeto de análisis pertenece, como lo ha considerado expresamente el legislador suizo, al grupo de delitos de peligro común que afectan, en primer lugar, a la colectividad y, en segundo plano, a la vida e integridad corporal de las personas.

La complejidad de las sociedades modernas aumenta y los comportamientos peligrosos, lícitos o ilícitos, se intensifican debido, principalmente, a que entre los participantes de la actividad económica, 
financiera y de servicios, las empresas juegan un papel cada vez más importante. En el campo de la construcción, ellas hacen factible que se proyecten y ejecuten edificaciones cada vez más grandes y diversas, lo cual da lugar a que, de manera más frecuente e intensa, se produzcan situaciones riesgosas. Este factor ha coadyuvado a acentuar la tendencia a reconocer la responsabilidad penal de dichos entes colectivos.

En un país como Suiza, y conforme a su legislación, cabe destacar que los comportamientos relevantes en el ámbito del control penal en materia de la construcción están constituidos por los delitos que atentan contra los bienes individuales: la vida (homicidio culposo), la salud e integridad corporal (lesiones), el patrimonio (estafa, abuso de confianza, daños a la propiedad), la seguridad pública (p. ej., el delito materia de este análisis).

Debido a la condición de Estado confederal de Suiza, el estudio de esta figura punible en especial implica tener en cuenta las disposiciones legales de orden administrativo, pues a través de ellas se busca reforzar, a nivel federal, cantonal y comunal (Cfr. Riklin, 1986, p. 399), la eficacia de las directivas y los reglamentos destinados a garantizar el correcto desarrollo de la actividad de la construcción de edificios.

Así las cosas, en atención a la índole de este análisis, nos limitamos a presentar los diversos aspectos de la interpretación del tipo legal contenido en el artículo (art.) 229 del Código Penal (CP); lo anterior, puesto que aun la simple descripción de los demás aspectos relacionados con esta incriminación implicaría sobrepasar el marco fijado.

Según dicha disposición:

Violación de las reglas del arte de construir.

1. Quien, dirigiendo o ejecutando una construcción o una demolición, viola intencionalmente las reglas del arte y, a sabiendas, pone en peligro la vida o la integridad corporal de las personas, es castigado con pena privativa de la libertad no mayor de tres años o pena pecuniaria. En caso de pena privativa de libertad, una pena pecuniaria será igualmente pronunciada.

2. La pena es privativa de libertad no mayor de tres años o pena pecuniaria si el autor viola culposamente las reglas del arte.

Antes de la unificación de la legislación penal suiza, los códigos penales cantonales no preveían una disposición similar al art. 229; 
su inserción y redacción fue discutida ampliamente en el seno de las diversas comisiones, los debates se reflejan en las distintas modificaciones de los textos propuestos. Para la muestra basta un ejemplo: inicialmente, se hacía referencia a 'Quien en ocasión de trabajos de construcción' (Wer bei Bauarbeiten) y a 'dirigido o ejecutado trabajos' (dirigé ou exécuté des travaux) (Gautier, 1916, p. 367), luego en el art. 195 del proyecto definitivo de 1918 se usó la fórmula 'dirigiendo o ejecutando trabajos' (en dirigeant ou en exécutant); la misma que fue definitivamente conservada en el texto del Código, prefiriéndose así muy probablemente el modelo alemán.

\section{Derecho comparado}

El § 330 del derogado Código Penal alemán establecía que se “impondrá una multa o la pena de prisión no mayor de un año a quien, dirigiendo o edificando una construcción hubiera violado las reglas generalmente reconocidas en arquitectura de modo que resulte un peligro para tercero". En este texto solo se mencionaba a la 'construcción'; sin embargo, la doctrina y la jurisprudencia interpretaron esta expresión de manera que comprendía también la demolición. En el $\S 319$, substituto del derogado $\S 330$, se dice expresamente 'construir' y 'demoler'.

En el Código Penal austríaco, no se consigna disposición específica sobre la puesta en peligro ocasionada en la ejecución de trabajos de edificación. Los delitos de peligro relacionados con esta actividad se hayan comprendidos en un grupo amplio de puesta en peligro colectivo, es decir, de una gran número de personas ( $\$ 176$ CP austríaco) (Roelli \& Fleischanderl, 2007, art. 229 n. 2).

En Francia, la situación es similar, pues no se prevé en el Código Penal disposición alguna que incrimine la puesta en peligro de la violación de las reglas admitidas en la actividad de construir (Roelli \& Fleischanderl, 2007, art. 229 n. 1). No obstante, en el art. 437 del Código derogado se reprimía el hecho de demoler intencionalmente, de forma total o parcial, una construcción, con el agravante de que una persona resulte lesionada o muerta. De acuerdo con el nuevo Código, en su art. 322-6, inc. 1, se castiga a quien ocasione la "destrucción, degradación o deterioro de un bien perteneciente a un tercero mediante una substancia explosiva, un incendio o cualquier otro medio de la naturaleza que pueda crear un peligro para las personas" (Roelli \& Fleischanderl, 2007, art. 229 n. 1). 
En Italia, el art. 434 del Código Penal, designado bajo el rubro 'destrucción de construcciones u otros daños intencionales', no menciona las reglas del arte de construir; solo se limita a las consecuencias del acto delictuoso cometido intencionalmente; de modo particular, a la destrucción cuyas consecuencias amenacen la seguridad pública (Roelli \& Fleischanderl, 2007, art. 229 n. 2). Por su parte, en el Código Penal español, en el Título XVII denominado 'De los delitos contra la seguridad colectiva' dentro de su Capítulo I titulado como ‘De los delitos de riesgo catastrófico', se prevé el art. 350 (Monge, 1997) en el cual se dispone que se reprimirá a

los que en la apertura de pozos o excavaciones, en la construcción o demolición de edificios, presas, canalizaciones u obras análogas o, en su conservación, acondicionamiento o mantenimiento infrinjan las normas de seguridad establecidas cuya inobservancia pueda ocasionar resultados catastróficos, y pongan en concreto peligro la vida, la integridad física de las personas o el medio ambiente.

Las penas a imponer, previstas en el art. 449 (manipulación, transporte o tenencia de organismos que ponga en peligro la vida, la integridad física o la salud de las personas, o el medio ambiente, contraviniendo 'las medidas de seguridad establecidas'), son las de prisión de seis meses a dos años, multa de seis a doce meses, e inhabilitación especial para el empleo o cargo público, profesión u oficio por tiempo de tres a seis años.

El citado art. 350 entra en concurso con el art. 316 (Delitos contra los derechos de los trabajadores) (Boix \& Orts, 2001, p. 59 y ss.), en el cual se establece que quienes,

Con infracción de las normas de prevención de riesgos laborales y estando legalmente obligados, no faciliten los medios necesarios para que los trabajadores desempeñen su actividad con las medidas de seguridad e higiene adecuadas, de forma que pongan así en peligro grave su vida, salud o integridad física, serán castigados con las penas de prisión de seis meses a tres años y multa de seis a doce meses.

La comisión culposa de este delito también es punible conforme al art. 317 .

Estas disposiciones deben ser consideradas teniendo en cuenta la legislación complementaria. En especial, por ejemplo, la Ley de prevención de riesgos laborales que, en sus arts. 47 y 48, establecen infracciones graves y muy graves. En el inc. 8 de este último, se 
dispone la de "no adoptar otras medidas preventivas aplicables a las condiciones de trabajo en ejecución de la normativa sobre prevención de riesgos laborales de las que se derive un riesgo grave e inminente para la seguridad y salud de los trabajadores".

\section{Actividad concernida}

El comportamiento incriminado en el tipo legal debe cometerse "dirigiendo o ejecutando una construcción o demolición" (art. 229, inc. 1). El legislador delimita así un sector de actividad humana que comporta un peligro significativo para la vida, la salud o la integridad corporal de las personas (construcción y demolición de un bien inmueble) e igualmente las personas a las que se les puede imputar la responsabilidad (directores y ejecutantes).

La mención expresa de las dos formas de actividades 'construir y demoler' tiene la ventaja de descartar problemas de interpretación (Gautier, 1916, p. 367; Hafter, 1943, p. 519). En efecto, ambas están estrechamente vinculadas, dado que para construir un nuevo edificio, muchas veces es necesario destruir el antiguo y para renovar una casa es indispensable suprimir algunos elementos viejos e inservibles. Hafter (1943) afirmó en este sentido que "unter einem Bauwerk kann man zur Not auch Abbrucharbeiten verstehen" (p. 519). Por su parte el legislador no menciona las reglas referentes a la demolición por entender que estas se hayan comprendidas en las relativas a la construcción.

\section{Noción de construcción.}

De conformidad con la jurisprudencia (RO, 115 IV 45, c. 2b/JdT 1990 IV 112; RO 90 IV 249; decisiones no publicadas, 6P.166/2003 c. 7.2 et 6S.781/1995) y la doctrina (Bendel, 1960, p. 31; Gauch, 1985, n. 172; Logoz, 1956, II, p. 450; Riklin, 1985, p. 44; Roelli \& Fleischanderl, 2007, art. 229 n. 5; Stratenwerth, 2000, t. II, p. 120; Thormann \& Von Overbeck, 1941, t, II, p. 270), la idea de construcción debe ser interpretada extensivamente. Así, entonces, comprende todo lo construido sobre y en el suelo. Para el Tribunal Federal, el factor decisivo es el vínculo que une la instalación arquitectónica o técnica con la superficie. Se trata así, de edificios, carreteras y vías férreas como también de los elementos de las construcciones, siempre y cuando estén sólidamente fijados a la superficie como puentes, túneles, estructuras de alumbrado (6P.166/2003 consid. 7. 2., no publicada), canalizaciones, escaleras, ascensores, andamios o grúas (Riklin, 2003, p. 138; Roelli \& Fleischanderl, 2007, Art. 229 n. 5). 
Las ampliaciones, transformaciones, refacciones o renovaciones también son consideradas como construcciones (Corboz, 2002, Art.229 n. 6), por ejemplo, los trabajos realizados en la fachada de un edificio (RO 115 IV 45, c. 2b./JdT 1990 IV 112). Esto explica que el Tribunal Federal no haya descartado la responsabilidad penal del encargado de la construcción y mantenimiento de una escuela en el caso de un escolar víctima de una caída mortal en circunstancias en las que se utilizaba el pasamano de escalera para deslizarse (1P.305/2004, no publicada).

El término 'construcción' tiene diferentes significados en derecho penal, derecho público y aún en derecho civil. En este último ámbito, el art. 58 del Código de obligaciones se aplica no solo a los inmuebles, sino también a todo producto de la actividad humana que presenta, en la perspectiva económica, cierta analogía con los 'edificios inmuebles'. Se comprende así, desde esta perspectiva, a los "inmuebles y otros arreglos técnicos estables realizados por el hombre que están, directa o indirectamente, fijados al suelo" (RO 130 III 736/JdT 2006 I 178). El art. 371 del mismo Código solo se aplica a las 'construcciones inmobiliarias', instaladas fijamente al suelo de manera permanente (RO 120 II 214, c. $3^{\circ}$; Bendel, 1960, p. 31; Gauch, 1985, n. 172).

Contrario a lo anterior, en el derecho penal, el carácter durable o permanente no es condición obligatoria. Una obra provisoria puede igualmente constituir una construcción, como es el caso de los andamios (AR: OG 30.04.2002, AR GVP 2002 p. 85; RSJ 1964288 (décision du Tribunal d'arrondissement de Zurich); Bendel, 1960, p. 31; Logoz, 1956, art. 227, n. 2. a) bb), 450; Riklin, 1985, p. 44; Thormann/von Overbeck, 1941, 227, n. 270). La jurisprudencia del Tribunal Federal no excluye esta interpretación y, en una sentencia, ha dejado abierta la cuestión de saber si los rieles de una grúa pueden ser calificados de construcción (ATF 104 IV 96 (99); Trechsel, 2008, art. 229, n. 3). El Tribunal de distrito de Zúrich ha reconocido en una famosa sentencia que una 'carpa de feria' (Festhütte) constituía una construcción, en consideración a que es materialmente semejante a un edificio y su caída implica los mismos peligros. Sin embargo, nos parece superfluo este razonamiento analógico, pues la noción de construcción no supone necesariamente la fijación definitiva al suelo mediante fundaciones o medios mecánicos. Actualmente, los progresos técnicos permiten desplazar construcciones según las necesidades, por ejemplo, el transporte de barracas con ocasión de la construcción de carreteras; la construcción, en todo caso, debe tener una dimensión importante. La instalación de simples 
casetas higiénicas en el campo de una feria popular no debería ser comprendida en esta categoría.

Las explicaciones ya señaladas sobre el término construcción se refieren al resultado de la actividad que nos interesa. Cierto, son útiles para delimitar el ámbito de aplicación del art. 229, pero no son eficaces para fijar sus límites de modo exhaustivo. En efecto, además de la edificación y de la demolición, deben tenerse en cuenta todas las actividades anexas a la construcción. Como, por ejemplo, la instalación y la desinstalación de los elementos necesarios para construir en el lugar escogido, utilizar máquinas de construcción, renovación de edificios, colocación de elementos parciales (calefacción central, escalera, ascensor). En el dominio de la demolición, como en el de la construcción, debe apreciarse la actividad concernida de manera global y no solo respecto al resultado que se produce.

\section{Autor.}

En el caso de los delitos especiales 'Sonderdelikte', solo puede ser autor quien tiene la calidad particular indicada en el tipo legal; la misma que está determinada por el deber implícito que comporta. Si se trata de un deber específico que recae sobre la persona concernida, se trata de un delito especial verdadero 'echtes Sonderdelikt' (Hurtado, 2008, p. 163, n. 480; Roelli \& Fleischanderl, 2007, art. 229, n. 18). Este es el caso del delito previsto en el art. 229, dado que solo puede cometerlo quien dirige o ejecuta los trabajos, es decir, el director, el ejecutante o el director general de los mismos. No obstante, es indispensable destacar que quien 'dirige o ejecuta los trabajos', obra generalmente en el marco de una empresa y, en consecuencia, es de tomar en cuenta el art. $102 \mathrm{CP}$, referente a la responsabilidad penal de las empresas.

De acuerdo con esta disposición, para responsabilizar penalmente a una empresa debe comprobarse la imposibilidad de identificar al responsable individual y que la transgresión a la ley penal se deba a una deficiencia de organización de la empresa (Cfr. último acápite de este texto).

\section{Delito especial.}

Esta figura forma parte del grupo de delitos especiales, pero no de los llamados 'delitos profesionales'. Si bien es cierto que el agente debe reunir la calidad personal especial designada en el art. 229 'dirigir o ejecutar trabajos de construcción', esta condición puede 
llegar a tenerla cualquier persona. En esta condición de facto puede transgredir una regla del arte de construir, pues su comportamiento está firmemente condicionado por el respeto de dichas normas y de este hecho se deduce su responsabilidad al crear un peligro construyendo o demoliendo un edificio (ATF 126 IV 84, c. 2c bb)/ JdT 2000 I 494). Por lo tanto, el autor no debe ser un especialista en la construcción o en la demolición.

En la Exposición de motivos del Anteproyecto de 1908, Zürcher (1914, p. 276) afirmó que el técnico diplomado o el empresario experimentado no son los únicos que incurrirían en la pena fijada en el art. 229, sino que esta puede ser aplicada también a los obreros sin dejar de lado al propietario mismo, en el caso de que asuma la dirección, la ejecución de la construcción o la demolición de su casa. Sin embargo, este último caso es relativamente excepcional en la medida en que el propietario confía generalmente este tipo de trabajo a un profesional (Lackner, 1986, § 323, 3b; Velten, 1965, p. 68). Conviene, además, subrayar que el art. 229 se aplica tanto al lego como al profesional, desde el momento en que actúa como empresario, coempresario, subcontratista, jefe de obra, jefe de equipo, obrero especializado o no. El factor decisivo no es el peso de la carga formal asumida por el interviniente, sino, más bien, la índole de la tarea que cumple realmente.

El Tribunal Federal ha sostenido, por el contrario, en un caso atinente a la propiedad horizontal de un edificio, que el art. $229 \mathrm{CP}$ -en la medida en que reprime infracciones a las reglas del arte de construir- no es aplicable al propietario de un piso, al conserje y al administrador de la propiedad horizontal. Además, la ley no establece ninguna responsabilidad formal de los superiores respecto a los demás trabajadores, por lo cual el art. 229 CP solo les sería aplicable de acuerdo con el trabajo que han tenido a su cargo (Bendel, 1960, p. 41).

\section{Dirección de trabajos.}

Dirige los trabajos quien tiene el poder de decidir y de controlar el desarrollo de los actos destinados a construir o demoler. El director de trabajo fija el método y los medios necesarios; se trata de un poder de hecho que se establece con ocasión de ejecutarse los trabajos y él debe proceder de manera que sean respetadas las reglas del arte y las medidas de seguridad de la policía de construcciones. De acuerdo con la ley, no existe una responsabilidad formal (Zürcher, 1914, p. 276), de 
modo que una vinculación legal derivada de un contrato de obra no confiere automáticamente la calidad de director de trabajos (RO 104 IV 96/JdT 1979 IV 138). La dirección de trabajos puede ser confiada, por ejemplo, a un arquitecto, un ingeniero o un empresario; en las grandes construcciones, es frecuente que un ingeniero y un arquitecto sean los designados (Roelli \& Fleischanderl, 2007, art. 229, n. 20 ss.).

El director de trabajos tiene un poder jerárquico sobre los participantes en los trabajos, quienes están obligados a obedecer estrictamente sus órdenes. Si constata circunstancias que constituyen un peligro para sus subordinados y que tiene la posibilidad de evitar, tiene la obligación de suprimirlas o de disponer que las prescripciones de prevención de accidentes sean respetadas. Una simple llamada de atención respecto al riesgo, en lugar de establecer medidas de seguridad, no es suficiente para que se excluya su responsabilidad (RO 109 IV 15, 17, c. 2a), 6S.181/2002 c. 3.2.1., sentencia no publicada; Roelli \& Fleischanderl, 2007, art. 229, n. 8). Si quien dirige los trabajos delega sus poderes en un tercero, debe responder por la selección, instrucción y supervisión de su reemplazante, sin que esto exija una vigilancia permanente de su parte (RO 104 IV 96/JdT 1979 IV 138, 6B.516/2009 c. 3.3.1., sentencia no publicada; 6P.58/2003 c. 6.1; Roelli \& Fleischanderl, 2007, art. 229, n. 18).

Si un responsable debe ejercer su actividad en diversas obras, normalmente confía a un colaborador experimentado y capaz la tarea de instruir y de vigilar directamente a los obreros en una de esas obras para evitar riesgos de accidente; por lo cual a este último no se le puede reprochar haber incumplido su deber personal. No obstante, esto no excluye que pueda responsabilizársele por haber omitido tomar las medidas apropiadas para eliminar o reducir los peligros (ATF 104 IV 96, c. 5.).

Sin embargo, el simple hecho de que una persona asegure la dirección y la ejecución de una construcción no implica que sea penalmente responsable por cada violación de las reglas en una obra. Por el contrario, cada persona que participa en los trabajos debe asegurarse de que las reglas de construcción sean respetadas en su ámbito de acción. La amplitud de la responsabilidad de cada uno depende de la situación de hecho y se determina tanto sobre la base de las prescripciones legales y contractuales como de las circunstancias; esto resulta de la obligada división del trabajo en el lugar de la obra. Sin embargo, debe destacarse que los límites entre las diferentes actividades individuales son frecuentemente 
difusos y que, entonces, puede suceder que varias personas sean responsables (ATF 109 IV 15/17; 6P.58/2003 c. 6.1., no publicada; Roelli \& Fleischanderl, 2007, art. 229, n. 18).

\section{Arquitecto: vigilancia y dirección de trabajos.}

En Suiza, la vigilancia de los trabajos está generalmente a cargo de un arquitecto escogido por el titular de la construcción. En la mayor parte de los casos, este profesional no se limita a elaborar los planos, se trata más bien de un mandatario (Schumacher, 1986, p. 111; opinión diferente en Gauch, 1986, p. 10 ss.). Sus relaciones con el titular de la construcción y con los terceros están definidas en el Código de obligaciones, y el mandato específico y las reglas previstas en la norma 102 de la 'Société suisse des ingénieurs et architectes' (SIA) (1984). De estas normas, se deduce que "el director de trabajos no puede limitarse al papel de coordinador y observador, debe intervenir de manera activa, informarse, estudiar, discutir y rendir cuentas" (Tercier, 1983, p. 63).

Los servicios comunes del arquitecto en relación con la dirección de los trabajos según el art. 4.4 de la norma SIA 102, son, por ejemplo, la puesta en marcha de los planes de ejecución, la coordinación del conjunto de profesionales especializados y de empresarios en la ejecución de los diferentes trabajos. El arquitecto vigila y controla el conjunto de los trabajos, el aporte de los materiales y su calidad; además, constata los defectos eventuales y ordena las medidas a tomar para eliminarlas. Igualmente, observa que los plazos sean respetados.

Estos deberes suponen, de parte del arquitecto, el respeto de las reglas del arte de construir. A pesar de no estar obligado a intervenir o vigilar constantemente de modo detallado todos los trabajos, el arquitecto dispone de un real poder sobre la construcción. Mediante sus directivas a los empresarios y obreros, es responsable de las consecuencias perjudiciales que pueden sobrevenir; responde también por la falta de vigilancia cuando los comportamientos de terceros, contrarios a las reglas del arte, producen un peligro para las personas. No se trata, evidentemente, de una responsabilidad formal (Zürcher, 1914, p. 276) y absoluta (Cfr. Schumacher, 1986, p. 446), la misma es determinada según la índole del rol asumido por el arquitecto.

\section{Ejecución de los trabajos.}

Esta tarea la lleva a cabo quien realiza materialmente las labores destinadas a erigir o desmantelar un edificio (Roelli \& Fleischanderl, 
2007, art. 229, n. 28). El ejecutante proporciona un trabajo muy diversificado, el cual -según las directivas del empresario, del jefe de obras o del director de los trabajos- concreta ya sea los proyectos elaborados previamente o la idea que se tiene al momento de ejecutar la construcción (Bendel, 1960, p. 41; Lackner, 1986, § 323, n. 3; Scherer, 1965, n. 8, 1; Schönke \& Schröder, 2001, § 323, n. 16; Velten, 1965, p. 56). Puede tratarse, principalmente, de un jefe de equipo, obrero (Roelli \& Fleischanderl, 2007, art. 229, n. 29 y ss.). El art. 229 CP se aplica a todos los trabajos efectuados en la obra.

\section{Bien jurídico y objeto de la infracción}

Los delitos de puesta en peligro colectivo afectan, en primer plano, la seguridad pública, la cual debe ser comprendida como el conjunto de condiciones garantizadas por el orden jurídico, indispensables para salvaguardar otros bienes; su titular es cada individuo en tanto miembro de la colectividad o comunidad. No se trata, sin embargo, de la seguridad pública en sentido amplio, protegida por el derecho en general y, en particular, por el derecho penal. Mediante la protección de la seguridad pública, se busca reforzar la salvaguardia de los bienes jurídicos individuales; en el caso del art. 229, la vida, la salud y la integridad corporal de las personas.

De acuerdo con la definición misma de peligro colectivo, el agente no escoge deliberadamente la o las personas que conforman, en segundo plano, el objeto del delito. Es una cuestión dependiente del azar. En consecuencia, la cantidad de personas puestas en peligro no es el factor decisivo, sino más bien la indeterminación del número probable de víctimas (Hurtado \& Thormann, 2011, n. 1435). Estas personas pueden ser los participantes en la ejecución de los trabajos (p. ej., obreros, proveedores), pero también personas ajenas a la obra (p. ej., peatones, vecinos, conductores) (Bendel, 1960, p. 74; Hafter, 1943, p. 519; Roelli \& Fleischanderl, 2007, art. 229 n. 36). En efecto, el art. 229 CP está destinado a proteger la vida y la integridad corporal de las persona tanto en la obra, como de quienes contribuyen en su ejecución (ATF 115 IV 45, 48ss, c. 2 c)/JdT 1990 IV, p.116) o de terceros ajenos a los trabajos.

Según la ley, no se trata de terceros. El autor individual del acto incriminado no puede ser simultáneamente la víctima o, al menos, no puede ser la única persona puesta en peligro (Corboz, 2002, art. 229 n. 27; Roelli \& Fleischanderl, 2007, art. 229 n. 35). Si bien en 
la doctrina no hay duda en lo que se refiere al autor del delito, se discute mucho, por el contrario, respecto a los participantes en la comisión del delito (coautores, instigadores, cómplices). Gran parte de la doctrina admite que éstos no son protegidos mediante el art. 229 CP. Esta opinión no es convincente, principalmente cuando los participantes son numerosos (Bendel, 1960, p. 74 y bibliografía citada en Hurtado, 2008, n. 1435), lo que acontece con frecuencia en obras de gran envergadura. Por tanto, hay que aceptar la aplicación del art. 229 CP si uno de los participantes en el delito se encuentra, ocasionalmente, en dominio del peligro creado (véase más abajo).

\section{Delito doloso}

Según el art. 229, inc. 1 CP, el comportamiento incriminado debe estar constituido por los siguientes elementos: una violación dolosa de las reglas del arte de construir; la puesta en peligro de la vida, la salud o la integridad corporal de las personas; y que la conducta se lleve a cabo en la ocasión de dirigir o ejecutar una construcción o una demolición.

Acorde con el sentido literal de esta disposición, el elemento central (expresado por el verbo principal) es la violación de las reglas del arte de construir o demoler; la puesta en peligro es el resultado de esta violación. La dirección o la ejecución de los trabajos solo constituye el contexto material en el que el agente actúa.

Esta redacción ambigua se origina, probablemente, en la legislación y en la doctrina alemanas; en su proyecto, Stooss había previsto reprimir el hecho de crear intencionalmente un peligro colectivo para la vida y la salud de las personas. La comisión de expertos modificó este texto de la siguiente manera: "quien, por negligencia, hubiera dirigido o ejecutado una construcción o una demolición con la que se ponga en peligro la vida de las personas $(\ldots)^{\prime \prime}$. Esta nueva versión solo reprimía la forma culposa y el acto principal consistía en dirigir o ejecutar una construcción. La segunda comisión de expertos propuso sustituir la expresión 'por negligencia' por la de 'violación de las reglas del arte de construir'.

El texto definitivo fue redactado siguiendo el modelo del $\S 330$ del derogado Código Penal alemán. Mediante este breve recuerdo histórico, podemos detectar mejor la estructura de un tipo legal previendo un delito culposo, por lo cual parece preferible entender que el art. $229 \mathrm{CP}$ exige los siguientes elementos: dirigir o ejecutar 
una construcción o demolición violando las reglas del arte de construir (acto incriminado); y, la puesta en peligro de la vida, la salud o la integridad corporal de las personas (resultado).

\section{Comisión y omisión.}

Si se parte de la constatación de que el comportamiento incriminado consiste en la violación de las reglas del arte de construir, la manera de comportarse será determinada según la índole de la regla violada. Si es prohibitiva, consistirá en una acción de comisión, mientras que si se trata de una norma que impone una manera de obrar se tratará de una omisión (Corboz, 2002, 229 n. 16; Hurtado, 2011, n. 1283; Roelli \& Fleischanderl, 2007, art. 229 n. 7).

Por el contrario, se considera que el aspecto principal del comportamiento incriminado es el hecho de dirigir o ejecutar una construcción o una demolición, conforme a nuestra interpretación, la violación mediante omisión de las reglas del arte de construir no modifica el carácter (de comisión o de omisión) del comportamiento. Ella caracteriza más bien el aspecto subjetivo del comportamiento (Hurtado, 2008, n. 1335; Wolters/Horn, 2009, § 319, n. 3). Esto se explica si se tiene en cuenta el hecho de que la infracción ha sido descrita según la estructura de un tipo de delito culposo, según la cual una omisión (inobservancia del deber de prudencia, Unterlassungsmoment) acompaña siempre el comportamiento típico (Handlungsvollzug) (Wessels, 1980, p. 156-157).

En esta perspectiva, para distinguir más fácilmente la comisión de la omisión (impropia), conviene analizar separadamente el hecho de dirigir y el de ejecutar una construcción o una demolición.

En el primer caso, el comportamiento delictuoso constituirá con frecuencia un delito de comisión; por ejemplo, el director de trabajos realizados en el techo de una casa que, sin respetar las reglas del arte, encarga al jefe de equipo y a un aprendiz, para efectuar las reparaciones. Es también el caso del arquitecto, encargado de la dirección de trabajos, que planifica y dirige la ejecución de una construcción según un método inhabitual sin tener la formación ni la experiencia necesarias.

Tanto el director de trabajos como el arquitecto han efectuado actos positivos coloreados por una omisión (Wolters/Horn, 2009, $\S 319$, n. 9). Sus comportamientos estaban orientados a hacer algo, a 
'dirigir' trabajos de construcción de manera defectuosa 'fehlerhaftes Leiten'. Conforme a este criterio, ejecuta igualmente una acción de comisión quien, al dirigir una construcción, no interviene para alejar un peligro creado por los trabajadores o se abstiene de advertirles. Por ejemplo, quien a pesar de ser consciente de la prohibición de permanecer en el lugar de la excavación mientras una excavadora está en plena actividad, no le advierte el peligro a sus trabajadores (RO 101 IV 28/JdT 1976 IV 104); comete así un error en la dirección de los trabajos ('Leitungsfehler'). También, es el caso del arquitecto que no prevé un escape de aireación al construir un baño en el que había instalado un alumbrado a gas (RO 92 IV 86/JdT 1966 IV 75), o que no prevé la instalación de una baranda en un balcón.

En todo caso, el agente también puede actuar por omisión, más precisamente por comisión por omisión (omisión impropia), en razón a que el tipo legal menciona la producción de un resultado: la puesta en peligro. De acuerdo con el art. $11 \mathrm{CP}$, es así mismo punible quien, tendiendo el deber de garante, se abstiene de evitar que el resultado (perjuicio o puesta en peligro) se produzca.

El deber de proteger los bienes jurídicos o de vigilar una fuente de riesgos, deriva de las reglas aplicables a quien asuma el papel de director o realizador de trabajos de construcción o demolición. El incumplimiento de este deber, se concreta mediante comportamientos no conformes con los mandatos prescritos por ciertas reglas del arte de construir. Mediante esta abstención, el autor crea o aumenta el riesgo de dañar la vida o la integridad corporal (peligro concreto) (Hurtado, 2008, n. 1330). Por ejemplo, obra por omisión el ingeniero o el arquitecto que abandona la dirección de los trabajos sin hacerse sustituir por una persona competente (RO 104 IV 96/JdT 1979 IV 138).

En el ámbito de la ejecución de trabajos, la distinción entre delito de comisión y de omisión es bastante problemática y debe ser establecida caso por caso. Si un director de trabajos o un jefe de obra exigen a un obrero que ejecute un trabajo específico, por ejemplo, el de instalar un sistema de seguridad, y este último no cumple con las órdenes recibidas, su comportamiento constituirá una conducta omisiva. Por el contrario, si ejecuta el trabajo, pero de manera incorrecta (violando las reglas del arte), su comportamiento podrá ser comisivo. 
En la medida en que el delito previsto en el art. 229 CP es uno especial, cuya realización supone la violación de un deber particular, la distinción solo es útil en este ámbito para individualizar a la persona responsable de la omisión (entre quienes dirigen o ejecutan los trabajos). Quien dirige o ejecuta los trabajos es garante respecto al peligro que resulta, de modo que el participante en los trabajos de construcción o de demolición obligado a intervenir (Garantenstellung), solo puede ser responsabilizado por una omisión (RO 101 IV 28, c. 2a/JdT 1976 IV 104; Schultz, 1982, p.127; Wolters / Horn, 2009, § 319, n. 10).

\section{Inobservancia de las reglas del arte de construir.}

El comportamiento base del delito -el hecho de dirigir o ejecutar una construcción- es una acción que nada tiene de reprensible en sí misma, es hasta socialmente útil. Sin embargo, en ciertas circunstancias, comporta un peligro para la vida o la integridad corporal de las personas. Cabe anotar que este peligro no basta para hablar de delito, aún es indispensable que el autor obre violando las reglas del arte de construir, lo cual hace del incumplimiento un elemento indispensable del tipo legal.

La finalidad de las reglas del arte es garantizar el desarrollo normal de los trabajos de construcción y de proteger la vida y la salud de las personas; una parte de dichas reglas concierne directamente a la obra. Este es el caso del cálculo de la estabilidad o de la preparación y utilización de materiales. No obstante, las normas que integran medidas de seguridad, son mayoritarias debido a que su objetivo prioritario es proteger la vida y la integridad de las personas, determinando el nivel mínimo de exigencias propias de la construcción. Las reglas del arte sirven, por un lado, para asegurar la seguridad de la obra cuando se ejecutan trabajos de construcción y de demolición $\mathrm{y}$, por otro, para proteger a quienes utilicen la construcción una vez concluida (Corboz, 2010, art. 229, n. 12).

Algunas reglas del arte no conciernen directamente a la construcción o demolición en sentido estricto, pero están de alguna manera relacionadas con este dominio. Es el caso, principalmente, de las normas referentes al montaje y utilización de una grúa, o las medidas destinadas a proteger los edificios vecinos: el art. 103 de la norma SIA 118 prevé que el empresario debe tomar todas las medidas prescritas por la ley o aquellas recomendadas por la experiencia, para proteger la salud de las personas. 
Estas reglas del arte son fruto tanto de los progresos técnicos y científicos como de la experiencia. El fundamento científico, muy frecuente, no es sin embargo suficiente, pues una regla estatuida científicamente, aplicada raramente, no es reconocida; por ello, el Tribunal Federal no es del todo claro cuando afirma que,

Son reglas del arte de construir en el sentido del art. $229 \mathrm{CP}$, no solo aquellas que un práctico (...) conoce, sino igualmente aquellas leyes y reglas sobre las cuales solo los ingenieros y los arquitectos de formación universitaria están informados. Lo que es decisivo es el carácter indiscutido de las reglas en el estado actual de la ciencia (RO 106 IV 264/JdT 1982 IV 9).

Es indispensable todavía que la regla del arte sea reconocida y que este reconocimiento esté basado en una práctica probada (Gauch, 1999, n. 847).

Las reglas del arte pueden resultar de la experiencia de las personas activas en el dominio de la construcción. Se trata generalmente de reglas técnicas nacidas de la práctica, de los usos relativos al trabajo artesanal (Gauch, 1999, n. 846; Gauch, 1985, n. 592). Una regla del arte es, por su índole, una noción orientada hacia el pasado 'nosotros hemos procedido de esta manera', reuniendo en el presente todas las experiencias acumuladas hasta entonces (Roelli \& Fleischanderl, 2007, art. 229, n. 11). El uso muy extendido de una técnica incorrecta no debe ser considerado como regla del arte en el sentido del art. 229 CP.

\section{Fuentes.}

A diferencia de otras actividades sociales que presentan un peligro semejante para bienes jurídicos importantes, como la de la circulación vehicular, que son objeto de una reglamentación específica, las reglas del arte de construir se encuentran dispersas tanto en las legislaciones federal, cantonales y comunales, así como en las directivas de asociaciones profesionales que adquieren una importancia primordial (Roelli \& Fleischanderl, 2007, art. 229, n. 15 ss.). En este sector, la SIA tiene un papel esencial al establecer las directivas más difundidas e importantes (Cfr. norme SIA 118, Conditions générales pour l'exécution des travaux de Construction; Norme SIA 102, Règlement concernant les prestations et honoraires des architectes; Ordonnance concernant la prévention des accidents dans les travaux de construction (du 8 août 1967); Ordonnance concernant la prévention des accidents dans les travaux de toiture 
et les travaux exécutés sur les toits (du 17 novembre 1967); y la Ordonnance concernant les mesures destinées à prévenir des accidents dans l'emploi de grues et d'engins de levage (du 22 juin 1951), in RS 832.31). Las reglas del arte pueden también proceder de la costumbre, es decir, las prescripciones no escritas habitualmente seguidas por las personas de una profesión u oficio determinados. Es entonces necesario que la 'regla del arte' sea establecida en una ley, ordenanza o reglamento.

\section{Reglas reconocidas.}

Durante los trabajos preparatorios de la unificación del derecho penal, los expertos de la Segunda comisión emplearon fórmulas diferentes: 'Regeln der Baukunst', 'Regeln der Baukunde', 'Regeln der Technik' (Cfr. Gautier, 1916, p. 365 ss.; sobre el grado de reconocimiento de la regla, cfr. Roth, 1987, p. 35 ss., en particular p. 49). El texto definitivo, 'anerkannte Regeln der Baukunde', no corresponde plenamente a la fórmula francesa 'règles de l'art'. La jurisprudencia y la doctrina han privilegiado la versión alemana. La regla debe ser aceptada por las personas de la construcción, quienes deben aplicarla teniendo la convicción de su exactitud (Roelli \& Fleischanderl, 2007, art. 229, n. 11, n.13). Carece de trascendencia que sea recusada por el autor del acto y aún por un sector determinado; bastando así, que la norma sea generalmente reconocida por los especialistas (Roelli \& Fleischanderl, 2007, art. 229, n. 13). Sucede con frecuencia que se prevean nuevas reglas científicas correctas en reglamentos, pero que todavía no han demostrado su utilidad en la práctica. Tales reglas pueden sin embargo difundirse rápidamente, para luego comprobar su utilidad y acceder en poco tiempo al status de 'regla del arte reconocida' (Gauch, 1999, n. 851).

La fórmula 'reglas del arte', más exactamente 'die anerkannten Regeln der Baukunde', no es del todo correcta, pues el carácter normativo no es decisivo. Hay que tener en consideración más bien el aspecto material, porque debe tratarse de una exigencia que ha de respetarse para evitar el peligro. Los autores del Proyecto Alternativo alemán (Alternativ Entwurf, 1971, p. 83) propusieron incluso substituir la fórmula 'allgemeine anerkannte Regeln der Technik' por la de 'Anforderung der technischen Sorgfalt'. En su opinión, "damit soll eine ausschliessliche Regel vermieden, vielmehr eine Bestrafung auch dann ermöglicht werden, wenn technische Regeln sich noch nicht allgemeinen entwickelt haben oder veraltet oder unverständig sind". 


\section{Legalidad.}

Esta técnica legislativa, consistente en remitir a las reglas del arte, es empleada con frecuencia; en la doctrina se habla de leyes en blanco ('Blankettnorm'). En Alemania, esta técnica ha sidoampliamente criticada (Nikusch, 1967, p. 1811; Riklin, 1985, p. 45, con otras referencias), por considerarse que podría implicar la violación del principio de la legalidad, pues el legislador no establecería de manera precisa los comportamientos incriminados. La crítica estaría doblemente justificada respecto al art. $323 \mathrm{CP}$ alemán y al art. 229 CP suizo, debido a que estas disposiciones reenvían no solo a normas legales sino también a reglas establecidas por asociaciones profesionales privadas.

La objeción parece excesiva porque se basa en los alcances originales del principio de la legalidad, en el sentido que la descripción del comportamiento debía ser exhaustiva y precisa. Criterio actualmente superado si se tienen en cuenta tanto la imperfección propia del lenguaje en tanto medio de comunicación como la complejidad de los comportamientos humanos.

El reenvío a otras normas o reglas para completar la descripción del comportamiento delictuoso es necesario, en la medida en que este pertenece a un dominio de actividad que evoluciona constantemente, debido a los progresos técnicos y a las relaciones que se originan. El art. $229 \mathrm{CP}$ no remite a leyes del mismo rango (leyes en blanco llamadas impropias), sino a normas de nivel inferior (reglamentos administrativos, costumbre, etc.).

La referencia a la violación de las reglas del arte constituye en realidad el medio utilizado por el legislador para determinar el carácter ilícito de un comportamiento en principio permitido, pero que implica al menos algunos peligros. El tipo legal hubiera sido más impreciso si el legislador se hubiera limitado a describir el delito como el hecho de poner en peligro la vida o la integridad de las persona en ocasión de la dirección o ejecución de trabajos de construcción o demolición.

\section{Puesta en peligro.}

El delito previsto en el art. 229 es, como lo hemos señalado, un delito de peligro. No implica necesariamente, en consecuencia, que sobrevenga un daño. Basta, en efecto, que una dirección o ejecución defectuosa de trabajos haga nacer un peligro; este se debe entender 
como un estado especial, susceptible de provocar en las circunstancias del caso concreto un perjuicio a bienes jurídicos protegidos y que no se sabe certeramente por qué no se ha producido (Hafter, 1937, p. 48; Hurtado, 2008, n. 474; Germann, 1942, p. 244; Noll, 1954, p. 20; Willfratt, 1968, p. 235).

\section{Peligro colectivo.}

El art. 229 CP se encuentra en el séptimo título del Código (Crímenes o delitos que crean un peligro colectivo), junto a los delitos de incendio, inundaciones, explosivos, derrumbes, supresiones de aparatos protectores. Un aspecto particular de los delitos de peligro colectivo es el hecho de que afectan bienes jurídicos colectivos, aun cuando ponen indirecta y simultáneamente en peligro, bienes jurídicos individuales (Hurtado, 2008, n.1436). En nuestro caso, se trata del bien jurídico seguridad pública, cuyo titular es la comunidad; los bienes jurídicos individuales concernidos son la vida y la integridad corporal de las personas.

La noción de peligro colectivo puede ser determinada, como lo hace Logoz, de acuerdo con un criterio cuantitativo: el delincuente no amenaza a algunas personas determinadas sino a una colectividad y se sirve de medios apropiados para crear un peligro colectivo, por ejemplo, desencadenando una fuerza natural (el fuego, el agua, etc.); no obstante, este criterio cuantitativo es discutido. No es la cantidad de personas amenazadas el criterio que es determinante, sino el hecho de que un número indeterminado de seres humanos es el concernido. Puede tratarse de una sola persona o de un grupo determinado. Por ejemplo, el ingeniero que -sin tomar a sabiendas las medidas de seguridad indispensables- hace transportar bloques de betón a dos obreros, poniéndolos en peligro y, al mismo tiempo, creando un peligro para personas indeterminadas.

Así, para que exista peligro colectivo, basta que una sola persona, identificada o no, fuera del agente, se haya encontrado por azar en el ámbito de influencia de la situación peligrosa; amenazada por el azar, ella representa la colectividad. Esta apreciación del comportamiento se hace ex ante y poco importa que se realice una apreciación ex post; basta que una sola persona haya sido puesta en peligro (Stratenwerth, 1984, n. 2, p. 4). Desde esta perspectiva, el Tribunal Federal sostiene que el peligro colectivo es una noción amplia que se refiere a "una situación en la que probablemente bienes jurídicos pueden ser afectados en una medida que no es 
posible determinar ni delimitar previamente" (6B.834/2008; RO 117 IV 285/JdT 1993 IV 157; RO 85 IV 132/JdT 1959 IV 145; Stratenwerth, 1984, § 30 n. 14 ss., p. 107 ss.).

\section{Peligro concreto.}

En ciertos casos, el legislador reprime un comportamiento susceptible de poner en peligro bienes jurídicos, sin que sea necesario constatar la existencia real de este peligro; la doctrina habla entonces de 'peligro abstracto'. Este no implica la alteración del mundo exterior como efecto de la realización de un comportamiento incriminado; el carácter peligroso del comportamiento constituye la ratio de la incriminación penal: la simple realización de la acción implica ya la consumación del delito. En el caso de los delitos de peligro individual, señalemos el abandono de una persona lesionada (art. 127 CP) o la participación en una riña (art. 133 CP). El responsable es castigado por su comportamiento, abstención o comisión, sin tener en cuenta la efectividad de la amenaza.

El art. $226 \mathrm{CP}$ prevé un delito de peligro colectivo y abstracto. El legislador estima que la manipulación de explosivos o de gas tóxico presenta, en sí misma, un riesgo suficientemente importante para que no sea indispensable constatar una puesta en peligro concreta (Roelli \& Fleischanderl, 2007, art. 229, n. 35).

El hecho de construir o de demoler sin respetar las reglas del arte puede presentar este tipo de riesgos. Sin embargo, según el art. 229 $\mathrm{CP}$, es -por el contrario- necesario constatar una puesta en peligro para la vida o la integridad corporal de las personas. El delito previsto en esta disposición es, por lo tanto, un delito de peligro colectivo concreto, que implica la creación real de una situación peligrosa para bienes jurídicos (Hurtado, 2008, n. 1426).

Según los jueces federales,

[c]onstituye un peligro concreto la situación material en la que se presenta, de acuerdo con el curso ordinario de las cosas, la probabilidad o un cierto grado de posibilidad de lesionar un bien jurídico (...) sin que sea indispensable exigir un cierto grado de probabilidad matemática superior a 50 \%. (RO 58 I 218/JdT 1933 I 221; RO 97 IV 209.)

Por el contrario, si el acto del agente, según el curso ordinario de las cosas, es propicio para causar un perjuicio, pero el grado de probabilidad de dañar el bien jurídico concernido no es importante, 
no es posible hablar de peligro concreto. Principalmente, cuando las posibilidades de que el peligro se concrete son tan mínimas que no sería razonable admitir la probabilidad de un perjuicio. Tales actos solo podrían constituir un delito si la ley los calificara como tales (la actividad en cuestión), creando de esta manera un delito de peligro abstracto, independiente de las circunstancias (RO 58 I 218/JdT 1933 I 221; RO 97 IV 209).

Los criterios de la jurisprudencia son un poco imprecisos y pueden ocasionar diversos malentendidos. Por esto, la doctrina ha abandonado la exposición indicada, a favor de tener en cuenta la estructura de los tipos legales de los delitos de peligro. Es de preguntarse si el legislador ha hecho de la puesta en peligro uno de los elementos constitutivos del tipo legal. Si no es el caso, se puede sostener que el simple comportamiento incriminado es, en opinión del legislador, generalmente peligroso. Por el contrario, si el legislador prevé la puesta en peligro como elemento constitutivo del tipo legal, no bastará probar que el comportamiento del agente sea en sí peligroso, pues el juez debe constatar en concreto que el comportamiento ponga efectivamente en peligro los bienes jurídicos en cuestión. La incriminación del comportamiento se justifica por la perturbación provocada al titular del bien jurídico (Hurtado, 2011, p. 1426).

Las fórmulas utilizadas por el legislador para caracterizar los delitos de peligro concreto son diversas, como se constata con la lectura de los arts. 127 (exposición a peligro), 129 (puesta en peligro de la vida de un tercero), 223 (explosión), 227 (inundación) y 265 (alta traición) CP. Los jueces federales tienen igualmente en cuenta los criterios de la doctrina cuando afirman:

[s]e distingue, en doctrina, entre la puesta en peligro concreta y la puesta en peligro abstracta. La primera existe solo cuando el acto hace no solo posible la lesión desde el punto de vista subjetivo, sino también probable en el curso ordinario de las cosas (...) La segunda, por el contrario, supone tan solo que el legislador considera al acto mismo como peligroso y lo castiga en tanto tal sin exigir que el peligro se haya efectivamente manifestado. Basta entonces que el acto se apropiado para causar el perjuicio que el peligro hace temer (RO 90 IV 251-252/JdT 1965 IV 83).

\section{Relación de causalidad.}

Los delitos materiales comprenden los delitos de lesión y los delitos de puesta en peligro en concreto. Son llamados igualmente 
delitos de resultado, debido a que en su descripción legal, se prevé como elemento constitutivo, una modificación del mundo externo, física y cronológicamente diferenciada del comportamiento mismo. En estos casos, es indispensable constatar la relación de causalidad entre este último y el resultado producido. Así, el tipo legal del art. 229 CP solo es realizado si se constata la existencia de esa relación.

Para determinar la causalidad, la jurisprudencia y la doctrina predominante recurren principalmente al criterio de la causalidad natural; en determinadas circunstancias, principalmente en los casos culposos, el criterio aplicado es más bien el de la causalidad adecuada. Si un empresario (contratista), en contra de las reglas del arte de construir reconocidas, utiliza material inadecuado para construir las columnas portadoras de un edificio y crea de este modo un peligro de derrumbe, este solo puede ser considerado como el resultado de su comportamiento si, por pura hipótesis, al ser suprimido el resultado también desaparece (causalidad natural o equivalencia de las condiciones). Se trata en efecto de pronosticar, en función de ciertas circunstancias comunes, la manera en que una situación fáctica podría evolucionar. En la práctica, esto se reduce a constatar que el comportamiento del autor "es apropiado, en el curso ordinario de las cosas y según la experiencia de la vida, para producir o favorecer" el resultado (ATF 121 IV 212; ATF 122 IV 23; ATF 124 IV 119; Hurtado, 2008, n. 506; Noll, 1981, p. 218).

Una relación de 'pura posibilidad' existe entre la fuente del riesgo y el perjuicio futuro. En efecto, en una situación dada, el comportamiento puede o no desarrollarse en un sentido determinado y causar el perjuicio (Hurtado, 2008, n. 1419). La misma atingencia puede hacerse según que se aplique el criterio de la probabilidad (por el cual se busca saber si el resultado conocido era altamente probable) o aquel del riesgo (conforme al cual el comportamiento del autor debe haber creado el riesgo del resultado o, al menos, aumentado este peligro). Sin embargo, el primer criterio es preferible porque respeta mejor la prohibición de la presunción de culpabilidad (RO 101 IV 30/JdT 1976 IV 106). Además, la relación de causalidad es considerada excluida si el resultado tiene lugar debido a causas concomitantes que "constituyen circunstancias plenamente excepcionales o aparecen como correspondiendo a un comportamiento sí extraordinario, insensato o extravagante, que era imposible de esperarlo" (ATF 100 IV 283/JdT 1975 I 455; ATF 
Los problemas se multiplican cuando debe comprobarse una relación de causalidad entre una omisión y la puesta en peligro. Según la jurisprudencia y gran parte de la doctrina, la relación entre ambos es puramente hipotética; para apreciar la complejidad de la situación, basta con consultar algunas sentencias. El razonamiento de los jueces federales no es siempre claro, lo cual se explica en parte porque la persecución penal se lleva a cabo después de la materialización del peligro, por ejemplo después de la muerte o de las lesiones corporales. El Tribunal Federal analiza entonces la causalidad en relación con el resultado final y no sobre la relación entre el comportamiento del agente y la simple puesta en peligro, lo cual le permite aplicar el art. 117 CP (homicidio culposo) o el art. 125 $\mathrm{CP}$ (lesiones corporales culposas).

Veamos un ejemplo: en circunstancias en que las empresas $X$ y $Z$ ejecutaban trabajos de excavación para instalar tuberías de agua, un accidente se produjo. La excavadora de la empresa $X$ se encontraba en las cercanías de la intersección de dos trincheras en el momento en que algunos obreros trabajaban en el fondo de una de ellas. Cuando la excavadora fue puesta en funcionamiento se produjo un derrumbe que provocó la muerte de dos obreros y lesiones corporales a otros. A, que dirigía los trabajos en su sector, había estado en dos ocasiones en la obra y había constatado que la trinchera ejecutada por la empresa $Z$ estaba mal reforzada y que los obreros trabajaban en su interior. No les había dicho que estaba prohibido encontrarse en el interior mientras la excavadora estuviera en funcionamiento.

No advirtiendo a los obreros de la empresa $\mathrm{Z}$ del peligro de derrumbe, en contra de lo dispuesto en la ordenanza del Consejo Federal del 13 de setiembre de 1963 relativa a la prevención en los trabajos de excavación y de pozos, A violó las reglas del arte de construir. Según el Tribunal Federal, "absteniéndose de intervenir el recurrente ha faltado a la vigilancia prescrita en el art. 2 de la ordenanza antes citada y en consecuencia violado las reglas del arte en el sentido del art. 229, inc. 2 CP" (RO 101 IV 31/JdT 1976 IV 107). Como se produjo la muerte de dos obreros, A también es responsable de homicidio culposo, art. $117 \mathrm{CP}$. 

mó que,

La causalidad adecuada existe cuando tal causa, en el curso ordinario de las cosas, es apropiada para causar o provocar tal resultado. La causalidad adecuada no se presenta, por el contrario, cuando el hecho considerado se aleja a tal punto del curso ordinario de las cosas de acuerdo con la experiencia de la vida que no se le puede considerar como la consecuencia posible del hecho (...) Como la presente infracción procede de una omisión (omisión de advertir un peligro), no se trata de una relación efectiva sino de una relación supuesta. Se debe, en efecto, buscar si el resultado hubiese -en el curso ordinario de las cosas- sido evitado en caso de que el autor hubiera respetado su obligación de obrar (RO 101 IV 30 s./JdT 1976 IV 107).

Esta explicación de la causalidad no es conforme ni a la situación de hecho ni a las constataciones del mismo Tribunal Federal; este para rechazar la objeción de A, según la cual él no ejercía poder sobre los obreros de la empresa, afirmó que,

El hecho de no advertir a una persona en peligro no es en principio punible. Pero según una jurisprudencia constante quien crea una situación peligrosa para terceros debe tomar las precauciones exigidas por las circunstancias (ATF 90 IV 250 y las sentencias citadas) (RO 101 IV 31/JdT 1976 IV 106).

Esto significa que la omisión de una puesta en peligro de parte del director de trabajos es la causa del resultado según el Tribunal Federal. La advertencia del peligro debió haber tenido lugar una vez que el peligro había sido provocado por el comportamiento anterior: la dirección y ejecución defectuosas de los trabajos (excavación de una canalización mediante una excavadora sin respetar las reglas del arte). La relación de causalidad entre este comportamiento y la puesta en peligro de las personas no es por tanto analizada en el párrafo de la sentencia antes citada.

Estos dos aspectos diferentes de la situación de hecho son distinguidos por el Tribunal Federal, cuando dice

[e]n especial A y el conductor de la excavadora han creado un peligro de derrumbe o, al menos, aumentado este peligro. También el recurrente tenía la obligación de advertir no solo a sus propios obreros sino a todos aquellos que sus trabajos ponían en peligro ( $\mathrm{p}$. ej., menores jugando en la proximidad de la excavación) (RO 101 IV 31/JdT 1976 IV 106). 
El director de los trabajos dirige realmente la ejecución de la obra e incurre así en el comportamiento de comisión. Comete un error al abstenerse, luego de constatar que la canalización excavada por otra empresa estaba mal reforzada y que obreros se encontraban en su interior a pesar de que la excavadora estaba en funcionamiento. Su omisión caracteriza la modalidad incorrecta de su comportamiento de comisión (dirigir los trabajos). Constituye una inobservancia del deber de atención implícito al comportamiento cometido culposamente "(...) wo der Handlungsvollzug mit einem "Unterlassungsmoment" (d. h. mit der Ausserachtlassung der gebotenen Sorgfalt) verbunden ist (...)" (Wessels, 1980, p. 156).

El conductor de la excavadora ejecuta un trabajo de construcción: excavar una canalización. Se trata, entonces, de una conducta de comisión que crea primeramente un peligro colectivo (para un número indeterminado de personas), para luego provocar la muerte de algunas de esas personas. La omisión ('Unterlassungsmoment') comprendida en este comportamiento de comisión está constituida, pues, por la inobservancia de la ordenanza relativa a los trabajos de excavaciones y pozos. Es el comportamiento en su conjunto, caracterizado por la violación de las reglas del arte de construir, el que debe ser tomado en cuenta como causa del resultado y no solo la omisión. En el caso analizado es, por tanto, superfluo recurrir a la idea de 'causalidad hipotética'.

De lo expuesto se deduce, claramente, que la cuestión de la causalidad no es de orden puramente material y que su constatación no depende únicamente de los criterios de las ciencias exactas. Se trata más bien de una cuestión normativa que consiste en determinar bajo qué condiciones es oportuno imputar objetivamente el resultado al autor del comportamiento; en esta perspectiva, la imputación se da cuando se realizan las siguientes condiciones:

- existencia de una relación de causalidad según los criterios de las leyes naturales,

- creación o aumentación de un peligro no permitido por el orden jurídico,

- atribución del peligro al autor del comportamiento, y

- concreción del peligro prohibido por la norma.

El punto de partida es el hecho que, según las leyes naturales, la relación mínima que vincula al comportamiento con el resultado no sea excluido. Se trata, pues, de la aplicación del criterio de la 
causalidad natural señalado anteriormente. En el ejemplo antes dado, la insuficiencia del material empleado es, en principio, desde el punto de vista científico, capaz de crear un riesgo importante.

A este nivel, las dificultades pueden presentarse porque, aun con la participación de expertos, no se logra a veces demostrar, por ejemplo, que el origen del peligro es el material utilizado o la técnica empleada. Esto plantea también la cuestión de la llamada responsabilidad por el 'vicio oculto del producto' Produkthaftung, principalmente en el dominio de la comercialización y utilización de mercaderías.

Con miras a responder a la cuestión de la causalidad en este ámbito, se ha propuesto aceptar que es suficiente demostrar la ausencia de toda otra causa sustitutoria o de reserva 'Ersatz-oder Reserveursachen' (BGHSt 37, 106, caso: Produkthaftung: Lederspray); ello comporta reconocer que el producto es propicio a crear este peligro, sin tener que establecer los factores determinantes. Esta aptitud general a producir un efecto negativo (causalidad llamada estadística o general) es demasiado indeterminada (Schünemann, 2006, § 25 n. 196; Tiedemann, 2008, n. 172), aun cuando recuerda a la causalidad adecuada.

En la perspectiva de la imputación objetiva, la constatación del lazo básico entre el comportamiento y el resultado, es facilitado por las prescripciones establecidas como reglas del arte de construir en las directivas de los especialistas (p. ej., las normas SIA). Sin embargo, la constatación primaria de esta vinculación es insuficiente para imputar el peligro concreto producido respecto a la vida o la integridad corporal de las personas. Es aún necesario constatar que, mediante su comportamiento, el autor ha originado una situación peligrosa que supera los límites (fijados por las reglas del arte de construir) del riesgo autorizado o tolerado (en el caso que nos interesa, el relativo a los trabajos de construcción). El peligro así creado debe corresponder a la índole de los actos del agente y debe concretarse en relación con la vida o la integridad corporal de un número indeterminado de personas. Además, este peligro debe ser aquel que la disposición correspondiente, en nuestro caso el que el art. $229 \mathrm{CP}$, busca evitar.

Si todas estas condiciones son reunidas, se concluye que todos los elementos del tipo legal han sido realizados y que esto es la obra del autor del comportamiento. Por tanto, la ejecución del 
delito, comprendida la 'relación de causalidad', le es imputada objetivamente.

\section{Tipo legal subjetivo: dolo.}

Obra intencionalmente quien lo hace con conciencia y voluntad (art. 12, inc. 2CP). La conciencia comporta el conocimiento del aspecto objetivo del tipo legal; es decir, de los elementos mencionados por el legislador para describir el comportamiento incriminado. En el caso del art. 229 CP, se trata de dirigir o ejecutar trabajos de construcción o de demolición, violar las reglas del arte de construir y crear un peligro para la colectividad, afectando así indirectamente los bienes jurídicos vida e integridad corporal de las personas. La voluntad, aspecto subjetivo del tipo legal, comprende la realización de cada uno de estos elementos.

Si el autor ignora o desconoce las circunstancias que le exigen respetar las reglas del arte de construir, obra bajo la influencia de un error sobre los hechos (art. $13 \mathrm{CP}$, Tatbestandsirrtum), por lo tanto, sobre el contenido de las reglas del arte o sobre las consecuencias prácticas del incumplimiento (Corboz, 2010, art. 229 n. 29); no actuaría dolosamente por lo que, llegado el caso, solo podría ser reprimido a título de culpa.

\section{Dirigir o ejecutar una obra.}

El dolo se refiere, ante todo, al hecho de dirigir o ejecutar una construcción o una demolición; esta intencionalidad no puede ser cuestionada. Al respecto, Lang precisó (Gautier, 1916, p. 366), durante los trabajos preparatorios relativos al inciso 2 del art. 229, que: "Die Fahrlässigkeit kann sich doch nur auf die Gefährdung beziehen, nicht auf die Leitung oder Ausführung des Baues".

\section{Violación de las reglas del arte de construir.}

El comportamiento incriminado no es solo el hecho de dirigir o ejecutar una construcción, sino más bien de dirigir o ejecutarla sin respetar las reglas del arte. La conciencia y la voluntad del autor se refieren igualmente a la calidad o, mejor, a la falta de calidad del trabajo que se le ha exigido. Por ejemplo, quien decide construir una columna menos resistente que aquella prevista por el ingeniero, o emplear materiales defectuosos. Esta manera de actuar supone que el autor tiene conciencia de las circunstancias materiales que le 
imponen proceder conforme a ciertas exigencias técnicas previstas en la lex artis.

\section{Puesta en peligro.}

De conformidad con el art. 229, inc. $1 \mathrm{CP}$, la puesta en peligro es un elemento del tipo legal; el autor debe saber que dirige o ejecuta una construcción sin respetar las reglas del arte y que actuando de esta manera pone en peligro la vida o la integridad corporal de las personas. Debe también querer cometer este comportamiento y su resultado. El Tribunal Federal ha admitido, al respecto, que "quien, con consciencia y voluntad, crea una situación de donde deriva, como él lo sabe, un peligro quiere necesariamente este peligro" (RO 94 IV 60(63)/JdT 1968 IV 75). Se trata, entonces, de un 'dolo de peligro' (Gefährdungsvorsatz) (Germann, 1942, p. 93).

Si el autor, cuando conoce la puesta en peligro potencial sigue, pese a ello, su actividad, quiere necesariamente esta puesta en peligro; así entonces, "no es indispensable que haya querido la realización del peligro, aún a título de dolo eventual, pues si lo hubiera querido sería responsable por comisión intencional del delito de lesión correspondiente (p. ej., homicidio)" (RO 94 IV 60(63)/JdT 1968 IV 75).

\section{Tipo legal subjetivo: a sabiendas.}

El tipo legal subjetivo es restringido en la medida en que la intencionalidad debe consistir en el conocimiento certero de que el comportamiento pone, realmente, en peligro la vida o la integridad de las personas; según los jueces federales si "bastara que el autor sea consciente del hecho de crear una posibilidad de peligro, la expresión 'a sabiendas' sería superflua, pues la consciencia de la posibilidad de peligro está comprendida en la noción de dolo eventual y no hubiera sido necesario mencionarla expresamente". El término 'a sabiendas' excluye el dolo eventual, pues este solo exige la consciencia de la probable realización del resultado (la puesta en peligro colectiva). El autor debe obrar con dolo directo en el marco del art. 229 CP (Roelli \& Fleischanderl, 2007, art. 229, n. 39).

\section{Tentativa y participación.}

El delito se consuma con la puesta en peligro colectiva (resultado típico); la tentativa es posible: el autor dolosamente viola las reglas 
del arte de construir para poner en peligro a las personas, pero este peligro no se produce y debe ser sancionado porque ha cometido una tentativa (Hurtado, 2011, p. 978).

La participación también es posible. Siempre es una intervención intencional y el animus, junto con la intensidad de la voluntad culpable, constituyen elementos decisivos (Hurtado, 2008, n. 1075; Roelli \& Fleischanderl, 2007, art. 229, n. 43). Como se trata de un delito especial, el Tribunal Federal admite que el extraneus (tercero que no dirige ni ejecuta la construcción) solo puede ser instigador o cómplice de quien tiene la condición de autor principal según el art. 229 CP (6P.22/2007, no publicada; RO 111 IV 74 /JdT 1985 IV 100; RO 95 IV 103(117)/JdT 1969 IV 112).

\section{Delito culposo}

\section{Tipo legal.}

La forma culposa del delito está prevista en el inc. 2 del art. 229 CP. De acuerdo con el art. 12, inc. $3 \mathrm{CP}$, obra culposamente quien, por una imprevisión culpable, actúa sin darse cuenta o sin tener en cuenta las consecuencias de su comportamiento, debido a que toma las precauciones exigidas por las circunstancias o su situación personal. En la práctica, la aplicación del art. 229, inc. 2, es más frecuente que la del inc. 1 de la misma disposición. Esto es debido a la índole misma de la actividad en cuestión, cuyo grado de tecnicidad y la evolución de los métodos favorecen los comportamientos negligentes; el tipo legal no refleja esta realidad. El texto del primer inciso es detallado, mientras que el del segundo no solo es breve, sino también defectuosamente redactado. Dice: "La pena será privativa de la libertad no mayor de tres años o una pena pecuniaria si la inobservancia de las reglas del arte son debidas a una negligencia".

\section{Relaciones con el dolo.}

Son dos las posibilidades imaginables en el marco de la aplicación de las nociones de dolo y culpa en el art. 229 CP. Partiendo de la idea que el comportamiento base del delito, a saber la dirección o ejecución de una construcción o de una demolición, es siempre consciente y voluntario, se pueden considerar cinco hipótesis:

1. X intencionalmente dirige o ejecuta una construcción o una demolición y viola también con intención las reglas del arte 
y pone, a sabiendas, en peligro la vida o la integridad corporal de las personas. Se trata de la hipótesis analizada en precedencia.

2. X de forma dolosa dirige o ejecuta una construcción o una demolición y viola también intencionalmente las reglas del arte y, de manera culposa, pone en peligro la vida o la integridad corporal de las personas. No se da cuenta o no tiene en cuenta los efectos de su comportamiento.

3. X dirige o ejecuta una construcción o una demolición y viola con culpa las reglas del arte, poniendo en peligro la vida o la integridad corporal de las personas; esta hipótesis, a pesar de su factibilidad, no está prevista en el texto del art. 229 CP.

4. X dirige o ejecuta una construcción o una demolición sin respetar, culposamente, las reglas del arte y pone en peligro, a sabiendas, la vida o la integridad corporal de las personas. Hipótesis que estaría prevista si se reemplazase el término intencionalmente del primer inciso por la expresión 'por negligencia'. Lo que no es el caso.

5. X viola culposamente las reglas de arte y, de modo negligente, pone en peligro la vida o la integridad corporal de las personas. Es esta hipótesis la que el legislador ha previsto reprimir en el art. 229 , inc. $2 \mathrm{CP}$, y que nos concierne de forma más directa.

El Código Penal alemán (Wolters \& Horn, 2009, § 319, n. 9), de manera más clara, prevé, por un lado, dos comportamientos dolosos de 'Baugefährdung' (planificar, dirigir o ejecutar trabajos de construcción o demolición sin respetar las técnicas generalmente reconocidas) y, por otro, primero, el caso de quien "ha causado el peligro por culpa $(. . .)^{\prime \prime}$ (§ $319 \mathrm{ch}$. 3) y, segundo, el hecho de crear el peligro culposamente mediante la realización de los comportamientos previstos en los numerales 1 y 3 .

\section{Deber de prudencia y reglas del arte.}

El art. 299, inc. 2 CP, como toda disposición que reprime un delito culposo, supone la violación de un deber de prudencia. De acuerdo con la jurisprudencia,

[p]ara que haya negligencia, es necesario que el autor haya violado las reglas de cuidado que las circunstancias le imponen para no 
sobrepasar los límites del peligro permitido y, además, que no haya prestado atención o no haya hecho los esfuerzos que podía esperarse, realice para respetar su deber (RO 133 IV 158, c. 5.1).

Este deber de prudencia, basado en el principio del respeto a bienes jurídicos de terceros, tiene, en el marco del derecho de la construcción, diversas fuentes. Las reglas del arte derivan de los deberes impuestos por la prudencia. Estos últimos pueden ser declarados en las normas establecidas por el orden jurídico para asegurar la seguridad y evitar los accidentes. A falta de disposiciones legales o reglamentarias, se encuentran en reglas análogas estatuidas por asociaciones privadas o semipúblicas (RO 129 IV 119, c.2.1/JdT 2004 IV 118). En efecto, las mismas reglas del arte, escritas o consuetudinarias, constituyen una fuenteesencial deestedeber deprudencia, principalmenteaquellas que conciernen las medidas de seguridad. Las circunstancias particulares en que tiene lugar el caso concreto (condiciones meteorológicas desfavorables, técnica elevada...) hacen surgir también la obligación de actuar con una prudencia especial, incluso cuando no existan en una prescripción formal (RO 106 IV 264/JdT 1982 IV 9). Este deber se generaliza, a veces, aplicando el criterio según el cual, quien practica una actividad implicando riesgos para terceros, está obligado a tomar las precauciones exigidas por las circunstancias (Schultz, 1982, p. 207). El art. 104 de la Norma SIA 118 precisa además que el "empresario toma las medidas de seguridad para prevenir accidentes y proteger la salud de las personas, el director de trabajos debe prestarle ayuda".

\section{Previsibilidad de la puesta en peligro.}

Un comportamiento solo puede ser culposo si el resultado es previsible; el agente debe tener la posibilidad de prever el desarrollo de los hechos según las circunstancias, sus capacidades individuales y las circunstancias materiales. Debe preguntarse, entonces, si el autor podía entrever, a grandes líneas, la evolución de los sucesos (RO 133 IV 158, c. 5.1). La especialización del agente o su experiencia en la construcción son elementos que permiten apreciar in concreto la previsibilidad del resultado (RO 133 IV 158; RO 129 IV 119/ JdT 2004 IV 118; RO 90 IV 246(251)/JdT 1965 IV 83; cf. RO 79 IV 170 s./ JdT 1954 IV 104). Es en el marco de la causalidad adecuada que el Tribunal Federal, buscando precisar las nociones de 'curso ordinario de las cosas' y 'experiencia de la vida', analiza la previsibilidad del resultado. Afirma de manera constante que un conocimiento exacto y preciso de la evolución de los hechos no es indispensable. 
X "hubiera debido pensar que terceros podían ser expuestos a peligro mediante los trabajos de excavación si sus obreros no eran advertidos de la presencia de conductos. Saber si podía y debía prever el desarrollo exacto de los sucesos es impertinente (...)" (RO 90 IV 246 (251)/JdT 1965 IV 83; cf. RO 79 IV 170 s./JdT 1954 IV 103 s). De modo que poco importa que el autor haya podido prever que los hechos pasarían precisamente tal como sucedieron (RO 115 IV 199, c. 5.c. /JdT 1991 IV 71).

\section{Culpa consciente e inconsciente.}

Según la noción de culpa prevista en el art. 12, inc. 3 CP, el autor puede obrar "sin darse cuenta de las consecuencias de su acción o sin tenerlo en cuenta". Si se da cuenta de la posibilidad de provocar un perjuicio mediante su accionar, subestima esta posibilidad y cree poder evitar su realización, se trata de una culpa consciente (ATF 90 IV 246 c. 1 b; Cfr. Hurtado, 2008, n. 1392). Actúa con culpa inconsciente cuando, debido a una desatención o falta de voluntad de actuar conforme a derecho para evitar la creación del peligro, no se da cuenta de las consecuencias de su acto e ignora el resultado concreto de su comportamiento (Hurtado, 2008, n. 1391).

La tercera hipótesis, imaginada al inicio de este capítulo respecto a la culpa, sobre la base del sentido literal del art. 229, inc. 2 CP, debe ser eliminada. Esta disposición no puede ser comprendida en este sentido: "quien, mediante culpa, hubiera infringido las reglas del arte dirigiendo o ejecutando una construcción o una demolición y hubiera de esta manera puesto en peligro, a sabiendas, la vida o la integridad corporal de las personas, será castigado (...)". La redacción defectuosa del art. $229 \mathrm{CP}$ es el origen de estos problemas de interpretación. La culpa concierne no solo a la violación de las reglas del arte de construir, sino también a la puesta en peligro de la vida y la integridad corporal de las personas (Cfr. Corboz, 2010, art. 229, n. 34; Logoz, 1956, art. 229, n. 5; Trechsel, 2008, art. 229 n. 10).

Por ello se dijo que la expresión 'a sabiendas' excluía, en la forma intencional del delito, el dolo eventual en relación con la puesta en peligro. Qué hacer, entonces, con quien viola intencionalmente las reglas del arte y, mediante dolo eventual, pone en peligro la vida de las personas. El problema es el mismo para quien de forma intencional vulnera las reglas del arte y pone culposamente en peligro dichos bienes jurídicos. Como no se puede aplicar el primer inciso del art. $229 \mathrm{CP}$, solo quedaría recurrir al inciso segundo; como 
este reprime un comportamiento a priori menos grave, se puede aceptar su aplicación para los casos mencionados. Gran parte de la doctrina admite esta solución cuya importancia práctica es muy pequeña (Bendel, 1960, p. 87).

\section{Culpa concomitante.}

La construcción o la demolición de una edificación comportan, como ya se ha señalado, diversos peligros. Los que participan en su realización están obligados a sujetarse a las reglas del arte y a usar la diligencia necesaria para respetar las reglas de seguridad (Cfr. Corboz, 2010, art. 229, n. 17). Cada uno puede esperar de los demás que se comporten también de acuerdo con esas reglas y, por tanto, con prudencia. La culpa de un tercero o de la víctima no es, sin embargo, suficiente para excluir la culpa de un participante, pues en el derecho penal no existe la compensación de culpas.

La puesta en peligro de la vida o la salud delas personas, raramente se debe a una sola circunstancia en la ocurrencia el comportamiento del agente. Se produce, más bien, por la concurrencia de diversos factores. Sucede con frecuencia que diversas personas sean responsables de una sola y misma violación de las reglas del arte, en razón de sus variadas competencias (Corboz, 2010, art. 229, n. 17). La responsabilidad del agente deberá entonces ser determinada según el papel que ha jugado, la índole y amplitud de sus deberes, que sea director de trabajos, contratista, jefe de equipo $u$ obrero calificado, etc.

Recuérdese el caso del director de trabajos que olvida informar a sus obreros que está prohibido permanecer en la excavación durante la ejecución de los trabajos. Según el Tribunal Federal:

[p]oco importa que los obreros hayan podido reconocer el peligro o alejarse espontáneamente del lugar. Cierto, no es necesario tener una formación para darse cuenta de que una canalización estrecha y profunda puede derrumbarse y causar la muerte de personas. Pero también se sabe que muchas personas descuidan peligros manifiestos, como ha sucedido en el caso sub iudice" (RO 101 IV 28(32)/JdT 1976 IV 107 ss.).

En otro caso, el Tribunal Federal admite que la confianza acordada a un subordinado no descarga de responsabilidad al titular de las obligaciones: 
[e]l hecho de que el colaborador más próximo del recurrente (arquitecto, director de trabajos) carezca de los conocimientos necesarios es superfluo. J. era responsable de la planificación y de la ejecución de los trabajos. No es necesario indagar si, en la hipótesis de que su colaborador hubiera sido mejor formado, le fuese atribuible una culpa. Precisamente, del hecho de que este colaborador fuera inexperimentado principalmente en este dominio, aquí cuestionado, de la estática, obligaba a J. bien a escoger un método de construcción con el que estuviera familiarizado, o bien, en consideración de la que ha escogido, a informarse o dirigirse a un especialista (RO 90 IV 246(251)/JdT 7965 IV 83; RO 106 IV 264/JdT 1982 IV 10).

La ausencia o insuficiencia de control de parte de las autoridades competentes no excluye automáticamente la responsabilidad del director de trabajos o de los ejecutantes. Un funcionario de policía de construcciones, que inspecciona y aprueba el conjunto de un edificio sin señalar defectos graves y peligrosos, no es pasible de aplicación del texto del art. 229 CP. Esto no quiere decir, sin embargo, que no se aplique a otros responsables. En un asunto de transporte de dalles en betón manualmente, el Tribunal Federal se pronunció señalando que,

[n]o era decisivo que, ni la autoridad cantonal que vigilaba la obra ni la Caja nacional no hubiesen intervenido para oponerse a dichos trabajos. Cuando se produce el accidente, los trabajos de coulage y de transporte de dichas dalles se realizaban desde hacía unos días. Que durante ese tiempo, los servicios de seguridad de obras y el asegurador hayan intervenido no permite afirmar que hubiesen aprobado los trabajos. Además, esta aprobación no excluiría necesariamente una imprevisión del empresario (RO 90 IV 8(13)).

\section{Sanción}

En caso de delito doloso, el autor puede ser castigado con pena privativa de libertad no mayor de tres años o con pena pecuniaria no mayor del límite superior indicado en el art. $34 \mathrm{CP}$; si la pena impuesta es privativa de libertad, se le aplica igualmente la pena pecuniaria. De esta manera, se tiene en cuenta que el delito es frecuentemente cometido por afán de lucro.

El legislador busca reprimir del modo más eficaz la violación de las reglas del arte de construir. Ha pensado en los casos más graves, por lo cual considera necesario imponer ambas penas en ciertos casos: "Busse ist gerechtfertigt, weil oft die Spartendenz die Bauleute zu fahrlässiger Begehung dieser Delikte verleitet" (Zürcher, 1914, p. 365), 
pues el agente muchas veces obra motivado por las ansias de ahorrar y así obtener mayor provecho económico.

Durante los trabajos de unificación del derecho penal suizo, esa orientación fue fuertemente criticada por las personas que actuaban en la construcción (Rohr, 1960, p. 30). Consideraban que así se castigaba, principalmente, a los empresarios menos pudientes, quienes son los más tentados a economizar. En el Anteproyecto de 1908 se consagró, en cierta medida, la opinión de la Asociación de artes y oficios, al preverse la prisión y la multa no mayor de veinte mil francos. Sin embargo, en el proyecto de 1918 se agravó la pena para el delito doloso. El texto actual prevé solo la aplicación alternativa de las mismas penas en caso de delito culposo.

\section{Prescripción de la acción penal}

De acuerdo con el art. 98 CP, el plazo de prescripción (Schultz, 1987 , p. 30) comienza a correr de tres maneras diferentes. En caso de delitos instantáneos, se inicia el día en que el delincuente ejecutó la actividad culpable (let. a). Si el delito es 'cometido en diversas ocasiones', se inicia el día en el que el último acto fue cometido (let. b). Tratándose de delito continuado, donde la ejecución tiene un lapso determinado, comienza a contarse a partir del día en que cesa la actividad delictuosa (let. c) (Hurtado, 2008, n. 1709). El legislador adopta el criterio de la acción ('Handlungstheorie') y rechaza la teoría del resultado ('Erfolgstheorie').

Es indispensable, por tanto, tener en cuenta la índole de la actividad incriminada, es decir, la descripción del comportamiento incriminado contenida en el tipo legal. Según las explicaciones precedentes, el delito del art. 229 CP consiste en poner en peligro la vida o la integridad corporal de las personas, mediante la violación de las reglas del arte de construir en ocasión de dirigir o ejecutar una construcción o una demolición. Se trata, primero, de un delito instantáneo ('Zustandsdelikt') (Roelli \& Fleischanderl, 2007, art. 229 , n. 50), que se consuma con el surgimiento de la situación ilícita que resulte del comportamiento indicado por el tipo legal. No constituye por ello un delito continuo 'Dauerdelikt' (Roelli \& Fleischanderl, 2007, art. 229, n. 50), pues el mismo implica que la situación ilícita perdure tanto tiempo como el agente continúe cometiendo el comportamiento prohibido. Tampoco es un delito de resultado porque este, para su consumación, supone la puesta en peligro concreta de la vida o la integridad corporal de las personas. 
No obstante, el comportamiento descrito en el art. 229 CP no es una acción singular como la correspondiente a otros delitos instantáneos (p. ej., homicidio: matar una persona envenenándola). El legislador prevé un comportamiento durable compuesto de diversos actos: el proceso de dirigir o ejecutar la construcción o la demolición, que dura un lapso más o menos largo y en ocasión a ello, el agente no respeta las reglas del arte de construir (unidad jurídica de acción). Cuando se trata de una conducta de comisión, el autor obra, si es arquitecto, todo el tiempo que orienta y controla los trabajos. Si es ingeniero o contratista, en todo el periodo que utiliza en construir la edificación; y si es obrero, el tiempo que dura la actividad que le ha sido asignada. Esto implica que el comportamiento puede tener lugar hasta el final de la actividad de construir o demoler (Roelli \& Fleischanderl, 2007, art. 229, n. 50). El punto de partida de la prescripción no es entonces ni el día en que el agente viola las reglas del arte de construir, ni el día en el que el resultado se produce (puesta en peligro de la vida o integridad corporal de las personas). Poco importa que el resultado se produzca más tarde o que la situación peligrosa perdure posteriormente. No se puede pretender que los actos culpables subsisten en la medida en que el peligro persiste: se considera que el agente actúa, mientras que el peligro debido a su culpa dura, teniendo el agente, el deber de intervenir (TF, 6S.449/2004, c. 2.1; Gless, 2011, p. 473 y ss.).

En una sentencia relativa a un accidente ocasionado con la puerta automática de un garaje, reparada varias veces durante los años siguientes a su instalación, el Tribunal Federal estimó que el plazo de prescripción había comenzado a correr en el momento de la instalación de la puerta en 1992 y no en el momento de las reparaciones ulteriores. Por ello, entendió que de las facturas de las reparaciones no se deducía que los trabajos hubieran comprendido el control de los elementos de seguridad (TF, 6S.449/2004, c. 3). Siendo el plazo de prescripción referente al art. $229 \mathrm{CP}$, conforme al art. 97, inc. 1, let. c CP, de siete años, la acción estaba prescrita en el momento del accidente (TF, 6S.449/2004, c. 2.2).

Si se trata de un comportamiento de omisión (p. ej., abstenerse de dirigir, de tomar alguna medida de seguridad), el plazo se inicia bien el día en que el autor tiene aún la posibilidad de intervenir o bien el día en que la obligación de intervenir ha cesado. Si un resultado fatal se produce con posterioridad a la culminación de los trabajos de construcción, el constructor puede ser declarado 
responsable (p. ej., de homicidio culposo por comisión por omisión). La prescripción de la acción penal por violación de las reglas del arte de construir puede haberse dado, pero la relativa al homicidio culposo comienza a contarse solo a partir de la producción del accidente. En efecto, cuando, por ejemplo, el responsable de la seguridad de una instalación (en el caso de un teleférico) omite, aun sabiendo que existía un problema capaz de poner en peligro a los usuarios y un accidente fatal se produce,

[e]l inicio de la prescripción coincide entonces, en materia de homicidio culposo, con el momento en que el autor ha actuado en contra de sus deberes de prudencia o, en caso de delito de omisión impropia, a partir del momento en que el garante debió obrar; si este deber perdura un cierto lapso, entonces la prescripción solo comienza a correr a partir del momento en el que las obligaciones de garante han culminado (TF, 6S.449/2004, c. 2.2; Cfr. ATF 122 IV 63).

En el derecho alemán, el art. 78A del CP alemán ('Die Verjährung beginnt, sobald die Tat beendet ist. Tritt ein zum Tatbestand gehörender Erfolg erst später ein, so beginnt die Verjährung mit diesem Zeitpunkt') prevé que la prescripción comienza a correr desde el fin de la actividad. Si se provoca con posterioridad un resultado relativo a la situación sobreviniente, la prescripción se iniciará en este momento precisamente. Antes de optar por esta solución clara, en Alemania existía una situación jurídica parecida a la suiza. Sin embargo, la jurisprudencia y parte de la doctrina brindaron una interpretación 'rectificadora', según la cual la prescripción solo podía comenzar en el momento en que todos los elementos constitutivos del delito, comprendido el resultado, estaban realizados; en otros términos, desde el momento en que la persecución penal era posible (Gless, 2011, p. 468; Roelli \& Fleischanderl, 2007, art. 229 n. 53).

\section{Responsabilidad penal de la empresa}

En la actividad de la construcción intervienen, de manera frecuente e importante, las empresas especializadas. La magnitud de las obras y los medios técnicos cada vez más perfeccionados, requieren que los constructores cuenten con los medios materiales y personales para practicar las edificaciones. Si en el marco de sus actividades, se comete el delito previsto en el art. 229 o, en concurso ideal o real, cualquier otro delito, se plantea la cuestión de la responsabilidad penal de la empresa misma (Hurtado, 2008, p. 385, n. 1196). 
De acuerdo con el sistema establecido en el art. $102 \mathrm{CP}$, la preocupación principal debe ser la identificación y sanción del o de los responsables individuales. Solo cuando no se logra identificarlos, se plantea la imputación penal contra la empresa. De acuerdo con el inc. 1 de esta disposición, la imputación procede a condición de que un delito haya sido cometido al interior de la empresa, en ocasión de una de sus actividades comerciales y conforme a sus fines, siempre y cuando dicho delito no pueda imputarse a una persona física 'debido a la falta de organización de la empresa'.

Respecto al art. 229, esto significa que la organización de la empresa debe tener graves carencias en relación con el control y la vigilancia de las actuaciones de sus miembros, a tal punto que resulta imposible identificar al responsable individual de la puesta en peligro de la vida e integridad de las personas mediante las reglas del arte de construir.

La imputación de responsabilidad penal a las empresas se explica, desde una perspectiva de política criminal, porque sus miembros, deliberada o indirectamente, favorecen el surgimiento de un contexto criminógeno debido a su falta de organización. De manera tal que la disolución u ocultamiento de las responsabilidades individuales, produce una responsabilidad colectiva (Hurtado, 2008, p. 393 p. 393 , n. 1223; Roth, 1997, p. 350). La deficiencia de organización, es la que da origen a la imposibilidad de identificar a la persona física responsable del delito, quien debe ser debidamente constatada (Hurtado, 2011, p. 27).

\section{Referencias}

Beck, U. (1998). La sociedad del riesgo (Trad. Martín Steinmetz). Barcelona: Ediciones Paidos Ibérica S.A.

Bendel, F. (1960). Die strafrechtliche Verantwortlichkeit bei der Verletzung der Regeln der Baukunde (Art.229 StGB). Ginebra.

Bendel, F. (1963). Die fahrlässige Tötung und Körperverletzung beim Bauen. Revue de droit pénal suisse, 79.

Bindhardt, W., \& Jagenburg, W. (1981). Die Haftung des Architekten. Düsseldorf: Werner-Verlag.

Boix, J., \& Orts, E. (2001). Consideraciones sobre el art. 316 del Código Penal. En U. d. Castilla, Homenaje al Dr. Marino Barbero Santos in memoriam (pág. 59 y ss). Cuenca: Ediciones Universidad Salamanca. 
Corboz, A. (2002). Le territoire comme palimpseste et autres essais. Besancon: D l'imprimeur.

Corboz, B. (2010). Les infractions in droit suisse, Vol. II, (3ºd.). Berna.

Del Arco Torres, M., \& Pons, M. (2003). Derecho de la construcción (aspectos administrativos, civiles y penales). Granada: Comares.

Ferler, A. (1954). Der strafrechtliche Schutz der Sache vor Beschädigung (Tesis de maestría/doctorado). Berna: Basel.

Gallas, W. (1963). Die strafrechtliche Verantwortlichkeit der am Bau Beteiligten (Unter besonderer Berücksichtigung des verantwortlichen Bauleiters). Heidelberg: Verlags-Gesellschaft Recht und Wirtschaft.

Gauch, P. (1985). Der Werkvertrag (3ºdicion). Zurich: Basel.

Gauch, P. (1986). Vom Architekturvertrag seiner Qualifikation und der SIA 102. En P. Gauch, \& P. Tercier, Le droit de l'architecte. Fribourg.

Gautier. (s.f.). Proces-verbal de la 2e Commission d'experts, III, 364.

Germann, O. (1942). Das Verbrechen im neuen Strafrecht. Zurich.

Gómez, M. (1997). Responsabilidad penal por riesgo en la construcción: análisis del artículo 350 del Código Penal (Tesis, Universidad de Sevilla).

Hafter, E. (1943). Schweizerisches Strafrecht . Berlín.

Hanspeter, K., \& Trechsel, A. (2008). The Politics of Switzerland, Continuity and change in a consensus democracy. Cambridge: Cambridge University Press.

Horn, E. (1973). Konkrete Gefährdungsdelikte. Köln: Otto Schmid.

Horn, E. (1985). En Systematischer Kommentar zum Strafgesetzbuch. Frankfurt: Luchterhand.

Hurtado, J. (2008). Droit pénal, Partie générale. Zurich: Schulthess Juristische Medien AG.

Hurtado, J. (2011). Droit pénal économique: questions de la partie générale. Zurich: Schulthess Juristische Medien AG.

Lackner, K. (1987). Festschrift für Karl Lackner zum 70. Geburtstag am 18. Februar 1987. Berlín: Walter de Gruyter.

Logoz, P. (1956). Commentaire du code pénal suisse. Revue internationale de droit comparé, 8 (1), 179-180. 
Löhner, O. (1907). Bauarbeiterschutz und Baupolizei in Bayern, $n^{\circ} 84 \mathrm{der}$ Münchener Volkswirtschaftlichen Studien. Munich: Stuttgart.

Monge, A. (1997). Responsabilidad penal por riesgos en la construcción: análisis del artículo 350 del Código Penal. Sevilla: Universidad de Sevilla.

Monge, A. (2012). La responsabilidad penal por riesgos en la construcción: Análisis del artículo 350 del Código Penal, (Tesis Doctoral, Universidad de Sevilla). Sevilla.

Nikusch, K.-O. (1967). § 330 als Beispiel fur eine unzulässige Verweisung auf die Regeln der Technik. Neue Jursitische Wochenschrift (NJW), 811 y ss.

Noll, P. (1954). Der subjektive Tatbestand der Gefährdung des Lebens nach Art. 129 des Strafgesetzbuches. Suiza: Stämpfli.

Noll, P. (1981). Schweizerisches Strafrecht. Zurich: Schulthess.

Riklin , F. (1986). Zum Strafrechtlichen Verantwortlichkeit des Architekten. En Le droit de l'architecte.

Riklin, F. (1985). Zum Straftatbestand des Art.229 StGB (Gefàhrdung durch Verietzung der Regeln der Baukunde). Baurecht.

Riklin, F. (1986). Zur strafrechtlichen Verantwortlichkeit des Architekten. Le droit de l'architecte, $397 \mathrm{y}$ ss.

Roelli, B., \& Fleischanderl, P. (2007). Art. 229. En M. Niglli, \& H. Wiprächtiger, Strafrecht II. Basel: Helbing Lichtenhahn Verlag.

Rohr, R. (1960). Die Gefährdung durch Verletzung der Regeln der Baukunde (Art. 229 StGB) . Zurich: Druck: Willisauer Volksblatt AG.

Roth, R. (1987). Le droit pénal face au risque et à l'accident individuels. Lausanne: Payot.

Roth, R. (1997). Responsabilité pénale de l'entreprise: modèles de réflexion. Revue pénale suisse, 345-381.

Schaumann, C. (1999). Rechtsprechung zum Architektenrecht. Freiburg: Schulthess.

Scherer, E. (1965). Strafrecht in der Baupraxis: Kommentar. Düsseldorf: Werner.

Schöncke, A., Horst, S., Lenckner, T., Eser, A., Peter, C., Stree, W., ... SternbergLieben, D. (2001). Strafgesetzbuch Kommentar. Munich: C.H. Beck.

Schubarth, M. (1982). Kommentar zum Schweizerischen Strafrecht. Berna: Stämpfli. 
Schultz, H. (1982). Einführung in den Allgemeinen Teil des Strafrechts. Berna: Stämpfli.

Schultz, H. (1987). Bericht und Vorentwurf zur Revision des Allgemeinen Teils des schweizerischen Strafgesetzbuches. Berna: Stämpfli.

Schumacher, R. (1986). Die Haftung des Architeckten aus Vertrag. En P. Gauch, \& P. Tercier, Le droit de l'architecte (pág. 105 y ss). Berna: Schulthess.

Schünemann, B. (2007). Kommentar des § 25 ff. StGB. En H. W.-v. Sann/ Klaus, Leipziger Kommentar, Großkommentar zum. Berlín.

Stratenwerth, G. (2000). Schweizerisches Strafrecht. Besonderer Teil II (5 ed.) Berna: Stämpfli.

Stratenwerth, G., Jenny, G., \& Bommer, F. (2000). Schweizerisches Strafrecht, BT II. Berna: Stämpfli.

Tercier, P. (1983). La loi, les normes er leurs compléments. En P. Gauch, \& P. Tercier, Droit de la construction (págs. 63-68).

Thormann, P., \& Von, O. (1941). Das schweizerische Strafgesetzbuch. Zurich: Schulthess \& Co.

Tiedemann, K. (2007). Wirtschaftsstrafrecht, Einführung und Allgemeiner Teil ; mit wichtigen Rechtstexten. Munich: Karl Heymanns.

Velten, J. (1965). Die Baugefahrdung (330 StGB). Eine strafrechtliche und kriminologische Untersuchung. Kiel.

Vitt. (1963). Die Veranlwortung der am Bau Beteiligten nach den Vorschriften der neuen Landesbauordnung. Die Bauverwaltung.

Wessels, J. (1980). Slrafrecht Allgemeiner Teil (10 Ed.). Karlsruhe: Hüthig Jehle Rehm.

Willfratt, M. (1968). Gefährdung des Lebens nach Art. 129 StGB. Revue Pénale Suisse.

Wirz, B. (1946). Der Schutz der Grundstücke vor Beschädigungen nach dem schweizer (Tesis, Universitaire BCU Lausanne). Lausanne.

Wolters, H. (2009). § 319. En R. Hans-Joachim, H. Eckhard, \& E. Samson, Systematischer Kommentar zum Strafgesetzbuch ( $8^{\circ}$ Ed.) (págs. 1-37,). Berlín: Carl Heymanns.

Zürcher, E. (1914). Exposé des motifs de l'Avant-projet (Trad. Gautier Alfred). Berna: Stämpfli. 



\section{III \\ Jurisprudencia}


